\title{
Genetic characterization of three mitochondrial gene sequences of goat/sheep-derived coenurus cerebralis and cysticercus tenuicollis isolates in Inner Mongolia, China ${ }^{\mathrm{a}}$
}

\author{
Yichi Zhang, ${ }^{\mathrm{a}, 1}$, Wei Zhao ${ }^{\mathrm{a}, 1}$, Di Yang${ }^{1}$, Yuan Tian², Weizhe Zhang ${ }^{1}$, and Aiqin Liu ${ }^{1, *}$ \\ ${ }^{1}$ Department of Parasitology, Harbin Medical University China; Harbin Medical University, Heilongjiang Provincial Key \\ Laboratory for Infection and Immunity; Heilongjiang Key Laboratory for Pathogen Biology, Harbin, Heilongjiang 150081, \\ PR China \\ 2 Department of MRI Scanning Room, the First Affiliated Hospital of Harbin Medical University, Harbin, \\ Heilongjiang 150001, PR China
}

Received 25 October 2017, Accepted 10 January 2018, Published online 19 January 2018

\begin{abstract}
Taenia multiceps and Taenia hydatigena are widely distributed tapeworms of canids. Due to a lack of genetic information on these two parasites in China, in this study we analyzed six coenurus cerebralis and two cysticercus tenuicollis cysts from goats or sheep in Inner Mongolia, northern China by amplifying three mitochondrial genes ( $\operatorname{cox} 1, n a d 4$, and $c y t b)$. Two haplotypes were obtained at each locus for either of the two Taenia cestode species, with ten nucleotide sequences being novel. The degrees of genetic variations were $1.18 \%$, $0.61 \%$ and $0.52 \%$ for coenurus cerebralis, and $0.24 \%, 0.46 \%$ and $0.35 \%$ for cysticercus tenuicollis at the cox 1 , nad4 and cytb loci, respectively. This is the first molecular description of animal-derived metacestodes of T. multiceps and T. hydatigena in Inner Mongolia, China. Novel nucleotide sequences might reflect endemic genetic characterization of the two cestodes. The present data are useful to explore the biological and epidemiological significance of intra-specific variations within both Taenia cestodes.
\end{abstract}

Keywords: Coenurus cerebralis, cysticercus tenuicollis, sheep, goats, mitochondrial gene

Résumé - Caractérisation génétique de trois séquences de gènes mitochondriaux d'isolats de coenurus cerebralis et de cysticercus tenuicollis de chèvre ou mouton en Mongolie intérieure, Chine. Taenia multiceps et Taenia hydatigena sont des ténias de canidés largement distribués. En raison de la quantité limitée de données génétiques sur ces deux parasites en Chine, les kystes de six coenurus cerebralis et deux cysticercus tenuicollis de chèvres ou de moutons de Mongolie intérieure, au nord de la Chine, ont été analysés en amplifiant trois gènes mitochondriaux ( $\operatorname{cox} 1$, nad4 et $c y t b)$. Deux haplotypes ont été obtenus à chaque locus pour l'une ou l'autre des deux espèces de Taenia, avec dix séquences nucléotidiques nouvelles. Les degrés de variation génétique étaient respectivement de $1,18 \%, 0,61 \%$ et $0,52 \%$ pour coenurus cerebralis et de $0,24 \%, 0,46 \%$ et $0,35 \%$ pour cysticercus tenuicollis, aux locus cox 1 , nad4 et cytb. Ceci est la première description moléculaire de métacestodes d'origine animale de T. multiceps et de T. hydatigena en Mongolie intérieure, Chine. De nouvelles séquences nucléotidiques pourraient refléter des caractérisations génétiques endémiques des deux cestodes. Ces données sont utiles pour explorer la signification biologique et épidémiologique des variations intraspécifiques au sein des Taenia.

\section{Introduction}

Taenia is a complicated genus of tapeworms composed of more than 40 accepted species, and in some of the species, subspecies have also been described [10,12]. Some members of the genus are responsible for taeniasis and/or

\footnotetext{
${ }^{a}$ Equal contributors

*Corresponding author: liuaiqin1128@126.com
}

cysticercosis in humans, and these helminthiasis diseases belong to the group of neglected tropical diseases. Coenurosis and abdominal cysticercosis are the most prevalent parasitic diseases worldwide in livestock; however, they primarily occur in sheep and goats in well-developed countries in areas of livestock husbandry $[18,23]$. The livestock are usually infected by ingesting grass contaminated with the eggs of Taenia multiceps (T. multiceps) and Taenia hydatigena (T. hydatigena) in 
the feces of definitive hosts, mainly including dogs and wolves [3]. These parasitic infections can cause a variety of clinical symptoms due to differences in the localization of cysts. Coenurus cerebralis is the most commonly found in the brain and spinal cord of sheep and goats, causing neurological disorders including ataxia, hypermetria, head deviation, headache, stumbling and paralysis [3]. The larva is also found in muscle, subcutaneous, and connective tissues, and other unusual locations [17,27]. Mature cysticercus tenuicollis cysts are usually found in the omentum, mesentery and peritoneum, less frequently in the pleura and pericardium and occasionally in the lungs, kidneys, brains, ovaries, uterine tubes, uterus, cervix, and vagina, while migrating larvae can be found mostly in the liver parenchyma $[24,26]$. In heavy infections, these larvae cause hemorrhagic and fibrotic lesions of liver parenchyma known as "hepatitis cysticercosa" [24,26]. Coenurosis and abdominal cysticercosis are usually fatal to livestock and cause huge losses to the economy due to condemnation of infected muscle and offal [9,21]. Human cases of coenurosis mostly result from accidental infections, and this disease has been found in South Africa, Europe, India, the USA, Brazil and Israel [13]. However, to date, only one human case of abdominal cysticercosis was recorded, which came from a Chinese four-year-old boy suffering from a stomach ache [31].

In China, coenurus cerebralis and cysticercus tenuicollis have been detected in animals from more than 20 provinces, and in western and north-western areas, where livestock husbandry is relatively developed, the species are mainly endemic. Infection rates are $2.7 \%$ to $53.0 \%$ for coenurus cerebralis and $1.3 \%$ to $12.5 \%$ for cysticercus tenuicollis in sheep in some provinces, and no epidemiological data are available in goats for either of the two parasites, and their genetic characterization is rarely recorded [14]. Northern Inner Mongolia is one of the most well-developed areas of livestock husbandry in China, accounting for up to $30 \%$ of total Chinese livestock production. To date, there have been only a few reports of T. multiceps and T. hydatigena in animals in this area, and they were all conducted in the $1990 \mathrm{~s}[7,30,33]$. To date, no information is available on genetic characterization of coenurus cerebralis and cysticercus tenuicollis in goats and sheep.

Mitochondrial (mt) genes are widely used as genetic markers and are preferred to nuclear genes in analyzing genetic characterizations and assessing genetic relationships of Taenia cestodes because of the maternal inheritance, higher mutation rate, rapid evolutionary rate, lack of recombination, and conserved structure [15]. In the present study, we molecularly confirmed one sheepand five goat-derived coenurus cerebralis cysts of T. multiceps and two goat-derived cysticercus tenuicollis cysts of $T$. hydatigena, and analyzed their genetic variations at three $\mathrm{mt}$ gene loci (cox1, nad4, and $c y t b)$ at the nucleotide and amino acid levels. The biological and epidemiological significance of intra-specific variations of metacestode cysts of T. multiceps and T. hydatigena was explored.

\section{Materials and Methods \\ Source of metacestode cysts}

Inner Mongolia is located in the north of China $\left(53^{\circ} 23^{\prime} \mathrm{N}, 97^{\circ} 12^{\prime} \mathrm{E}\right)$, including most of China's border with Mongolia and a small section of the border with Russia. It has a wide variety of regional climates due to its elongated shape. Most of this region is a plateau averaging around 1,200 meters in altitude. The annual average temperature is $6{ }^{\circ} \mathrm{C}$, with temperatures below $0{ }^{\circ} \mathrm{C}$ reached in October in the north and November in the south. During the period of time from July to September 2014, coenurus cerebralis cysts of T. multiceps (five from goats and one from a sheep) and cysticercus tenuicollis cysts of T. hydatigena from two goats were collected from an abattoir in Inner Mongolia. Specimen information, including code, species, location and size of each cyst in diameter as well as host sources, is shown in Table 1.

\section{Processing of endocysts and DNA extraction}

Cyst fluid of each of the larval cestodes was drained while the endocysts were preserved in $70 \%$ ethanol at $4{ }^{\circ} \mathrm{C}$ until further molecular analysis. Genomic DNA of larval cestodes was extracted from approximately $25 \mathrm{mg}$ cyst wall positive for scoleces using the DNeasy blood and tissue kit (Qiagen, Germany), according to the manufacturer's instructions. DNA was eluted in $200 \mu \mathrm{L}$ of Buffer AE and was stored at $-20^{\circ} \mathrm{C}$ until further use in PCR analysis.

\section{PCR amplification}

The partial cytochrome c oxidase subunit I ( cox1), NADH dehydrogenase subunit 4 (nad4) and cytochrome b (cytb) genes of eight metacestode cysts of T. multiceps and T. hydatigena were amplified in the present study. All the primers used here and the cycle parameters of PCR amplifications were described previously, and the objective gene fragments with the size of $455 \mathrm{bp}, 667 \mathrm{bp}$ and $570 \mathrm{bp}$ were acquired, respectively $[5,8,32]$. TaKaRa Taq DNA Polymerase (TaKaRa Bio Inc., Tokyo, Japan) was used for all the PCR amplifications. A negative control with no DNA was included in all the PCR tests. All the PCR products were subjected to electrophoresis in $1.5 \%$ agarose gel and visualized by staining the gel with ethidium bromide.

\section{DNA sequencing and data analysis}

All the PCR amplicons of the excepted size were sequenced with PCR primers at each locus on an ABI PRISMTM 3730 DNA Analyzer (Applied Biosystems, Carlsbad, CA, USA), using a BigDye Terminator v3.1Cycle Sequencing kit (Applied Biosystems, USA). The accuracy of the sequencing data was confirmed by sequencing in both directions. Nucleotide sequences obtained in the present study were congregated manually and were then subjected to BLAST searches (http:// www.ncbi.nlm.nih.gov/blast/). Aligned sequences were 
Table 1. Specimen code, location and size as well as host sources of metacestode cysts.

\begin{tabular}{lllll}
\hline $\begin{array}{l}\text { Specimen } \\
\text { code }\end{array}$ & $\begin{array}{l}\text { Taenia } \\
\text { species }\end{array}$ & Host & Location & $\begin{array}{l}\text { Cyst diameter } \\
(\mathrm{cm})\end{array}$ \\
\hline IM1 & T. multiceps & Sheep & $\begin{array}{l}\text { Mesentery of } \\
\text { small intestine }\end{array}$ & 3.5 \\
IM2 & T. multiceps & Goat & Brain & 1.5 \\
IM3 & T. hydatigena & Goat & Intestine & 2.2 \\
IM4 & T. hydatigena & Goat & Intestine & 1.3 \\
IM5 & T. multiceps & Goat & Brain & 1.8 \\
IM6 & T. multiceps & Goat & Brain & 1.4 \\
IM7 & T. multiceps & Goat & Brain & 2.1 \\
IM8 & T. multiceps & Goat & Brain & 1.6 \\
\hline
\end{tabular}

compared and analyzed with each other and reference sequences downloaded from GenBank using ClustalX 1.83 (http://www.clustal.org/).

\section{Phylogenetic analysis}

To present the genetic relationship of T. multiceps and T. hydatigena isolates obtained in the present study and published in GenBank as well as other members of the genus Taenia, the phylogenetic trees of the $\operatorname{cox} 1$, nad/4 and $c y t b$ gene sequences were constructed, respectively, using the neighbor-joining method with a Kimura-2-parameter model. The reliability of these trees was assessed using the bootstrap analysis with 1000 replicates.

\section{Results and Discussion}

In the present study, eight metacestode cysts were successfully amplified at the cox1, nad4 and cytb loci. The results of pairwise comparison of nucleotide sequences indicated the genetic heterogeneity within coenurus cerebralis and cysticercus tenuicollis at three mt loci. Two haplotypes were obtained at each locus for both of them. Meanwhile, a lesser degree of intra-specific nucleotide variation was observed within coenurus cerebralis in the mt genes of $\operatorname{cox} 1$ (1.18\%), nad4 (0.61\%) and cytb $(0.52 \%)$. Only two base mutations caused amino acid changes, which occurred at the nad4locus. Coenurus cerebralis was observed to have more common genetic variations at the cox1locus in the present study than in two recent studies, where five and seven haplotypes were defined among 105 and 102 coenurus cerebralis isolates from Greece and Iran, respectively [2,22]. For cysticercus tenuicollis, the degrees of intra-specific nucleotide variation were $0.24 \%, 0.46 \%$ and $0.35 \%$ at the cox 1, nad 4 and $c y t b$ loci, respectively. Only three base mutations caused amino acid changes, with one and two in the nad 4 and $c y t b$ genes, respectively. Homology analysis of nucleotide sequences revealed that ten of twelve representative nucleotide sequences were not described previously (Table 2). Representative nucleotide sequences obtained in this study were deposited in the GenBank database under the accession numbers KT258024 to KT258035.
These novel sequences might reflect endemic genetic characterizations of $T$. multiceps and T. hydatigena. In phylogenetic analysis, it was observed that at the cox1 locus, there was a lower bootstrap value (below 50) between T. hydatigena and T. multiceps as well as $T$. krabbei, T. serialis and T. saginata (Figure 1). The result might be related to the partial cox1 gene sequences analyzed. Meanwhile, it also implied the amplified gene fragment (423 bp at nucleotides from 719 to1142) was not good enough in resolution for inter- and intra-variation of Taenia species. Sequence analysis of the complete cox1 gene will be performed in the future to provide accurate phylogenetic relationships of the members of the genus Taenia as well as genetic variation within Taenia species.

Currently, the significance of the nucleotide and amino acid changes within coenurus cerebralis or cysticercus tenuicollis is unclear. However, genetic variability was reported previously to lead to phenotypic differences in many cestodes [16]. Varcasia et al. also pointed out that the presence of some clinical variations in coenurosis can indicate the existence of genetic intra-specific variability within T. multiceps [29]. It was speculated that the intraspecific sequence variations might represent the ability of these parasites to rapidly adapt to new intermediate host species as well as sites of infection occupied by the larval stages in different hosts [27]. In our study, five coenurus cerebralis cysts from the brain produced the same nucleotide sequence and were different from those from the mesentery of the small intestine at each locus (cox1, nad4 and cytb). A previous comparative study of experimental cerebral and non-cerebral coenurosis in goats indicated that the cysts of two groups were $100 \%$ identical to each other at the cox1 and nad1 loci [1]. In a recent study conducted in Turkey, different cox1 haplotypes of coenurus cerebralis were found in the same parasitic body part (brain) in sheep [25]. Identical sequences of coenurus cerebralis were also found in different hosts and different body parts: cox1 sequences (396bp) in the muscle of a goat (KT253993) and in the brain of a sheep (KT253934) [19]. In an investigation of the genetic variation and population structure of cysticercus tenuicollis from intermediate hosts, cysticercus tenuicollis isolates from sheep were observed to be differentiated from those of goat and pig origin at the nad1 locus; in addition, the goat-derived isolates were genetically different from adult $T$. hydatigena as indicated by the statistically significant Fst value [4]. Whether sequence differences are related to clinical features and/or organ preference needs to be explored in the future by analyzing other coenurus cerebralis and cysticercus tenuicollis cysts.

Variability in measurements of coenurus cerebralis cyst size has been documented. In the present study, the average size in diameter was $1.98 \mathrm{~cm}$ for coenurus cerebralis cysts and $1.75 \mathrm{~cm}$ for cysticercus tenuicollis cysts. Coenurus cerebralis cysts are considered to be typically $2-5 \mathrm{~cm}$ in diameter, and occasionally exceed $10 \mathrm{~cm}$ [13]. In a necroscopy, two cysts ( 49 and $23 \mathrm{~cm}^{3}$ ) were found in the brain of a bull in Italy [28]. In the United Arab Emirates, the size of the coenurus cerebralis cysts varied 
Table 2. Homology analysis of T. multiceps and T. hydatigena isolates at the three mitochondrial loci.

\begin{tabular}{|c|c|c|c|c|c|}
\hline Taenia species & $\begin{array}{l}\text { Loci } \\
\text { amplified }\end{array}$ & $\begin{array}{l}\text { Accession no. }{ }^{\mathrm{a}} \\
\text { (Specimen code) }\end{array}$ & $\begin{array}{l}\text { Accession } \\
\text { no. }^{\text {b }}\end{array}$ & Homology & Codon $^{\mathrm{c}} /$ Amino acid (Nucleotide Position) ${ }^{\mathrm{d}}$ \\
\hline \multirow{6}{*}{ T. multiceps } & \multirow[b]{2}{*}{$\cos 1$} & KT258024 (IM1) & EF393620 & $100 \%$ & \multirow[b]{2}{*}{$\mathrm{CC}(\mathrm{A}$ to $\mathrm{G}) / \mathrm{P}(76) ; \mathrm{GT}(\mathrm{T}$ to $\mathrm{C}) / \mathrm{V}(310)$} \\
\hline & & KT258025 (IM2, IM5-8) & JX507230 & $99.53 \%$ & \\
\hline & \multirow[t]{2}{*}{ nad4 } & KT258028 (IM1) & KC794808 & $99.09 \%$ & $\begin{array}{l}(\mathrm{G} \text { to } \mathrm{A}) \mathrm{TT} /(\mathrm{V} \text { to } \mathrm{I})(88) ; \mathrm{GC}(\mathrm{C} \text { to } \mathrm{T}) / \mathrm{A}(225) ; \\
(\mathrm{G} \text { to } \mathrm{A}) \mathrm{TG} /(\mathrm{V} \text { to } \mathrm{M})(529) ; \mathrm{AC}(\mathrm{T} \text { to } \mathrm{C}) / \mathrm{T}(570) ; \\
\mathrm{AG}(\mathrm{A} \text { to } \mathrm{G}) / \mathrm{S}(645) ; \mathrm{TC}(\mathrm{G} \text { to } \mathrm{A}) / \mathrm{S}(654)\end{array}$ \\
\hline & & KT258029 (IM2, IM5-8) & KC794808 & $99.70 \%$ & $\mathrm{GC}(\mathrm{C}$ to $\mathrm{T}) / \mathrm{A}(225) ; \mathrm{TC}(\mathrm{G}$ to $\mathrm{A}) / \mathrm{S}(654)$ \\
\hline & & KT258032 (IM1) & FJ495086 & $100 \%$ & \\
\hline & cytb & KT258033 (IM2, IM5-8) & JX546908 & $99.83 \%$ & $\mathrm{TC}(\mathrm{A}$ to $\mathrm{G}) / \mathrm{S}(379)$ \\
\hline \multirow{6}{*}{ T. hydatigena } & \multirow[b]{2}{*}{$\cos 1$} & KT258026 (IM3) & AB792724 & $99.53 \%$ & $\mathrm{TA}(\mathrm{C}$ to $\mathrm{T}) / \mathrm{Y}(13) ; \mathrm{TG}(\mathrm{G}$ to $\mathrm{A}) / \mathrm{W}(397)$ \\
\hline & & KT258027 (IM4) & AB792724 & $99.76 \%$ & $\mathrm{TA}(\mathrm{C}$ to $\mathrm{T}) / \mathrm{Y}(13)$ \\
\hline & \multirow[b]{2}{*}{$\operatorname{nad} 4$} & KT258030 (IM3) & KC794844 & $98.94 \%$ & $\begin{array}{l}\mathrm{TT}(\mathrm{A} \text { to } \mathrm{G}) / \mathrm{L}(39) ; \mathrm{AT}(\mathrm{C} \text { to } \mathrm{T}) / \mathrm{I}(69) ; \mathrm{TA}(\mathrm{C} \text { to } \mathrm{T}) / \\
\mathrm{Y}(150) ; \mathrm{G}(\mathrm{A} \text { to } \mathrm{G}) \mathrm{G} /(\mathrm{E} \text { to } \mathrm{G})(323) ; \mathrm{TT}(\mathrm{A} \text { to } \mathrm{G}) / \\
\mathrm{L}(615) ; \mathrm{TG}(\mathrm{C} \text { to } \mathrm{T}) / \mathrm{C}(651) ; \mathrm{TC}(\mathrm{G} \text { to } \mathrm{A}) / \mathrm{S}(654)\end{array}$ \\
\hline & & KT258031 (IM4) & KC794845 & $98.94 \%$ & $\begin{array}{l}\mathrm{TT}(\mathrm{A} \text { to } \mathrm{G}) / \mathrm{L}(39) ; \mathrm{AT}(\mathrm{C} \text { to } \mathrm{T}) / \mathrm{I}(69) ; \mathrm{TA}(\mathrm{C} \text { to } \mathrm{T}) / \\
\mathrm{Y}(150) ; \mathrm{CT}(\mathrm{A} \text { to } \mathrm{G}) / \mathrm{L}(159) ; \mathrm{TG}(\mathrm{G} \text { to } \mathrm{A}) / \mathrm{W}(333) ; \\
\mathrm{TG}(\mathrm{C} \text { to } \mathrm{T}) / \mathrm{C}(651) ; \mathrm{TC}(\mathrm{G} \text { to } \mathrm{A}) / \mathrm{S}(654)\end{array}$ \\
\hline & \multirow{2}{*}{$c y t b$} & KT258034 (IM3) & FJ518620 & $99.83 \%$ & $\operatorname{AT}($ A to $\mathrm{G}) /($ I to $\mathrm{M})(22)$ \\
\hline & & KT258035 (IM4) & FJ518620 & $99.83 \%$ & $\mathrm{GG}(\mathrm{C}$ to $\mathrm{T}) / \mathrm{G}(46)$ \\
\hline
\end{tabular}

a Accession no. indicating the representative sequences obtained in the present study.

b Accession no. indicating that the reference sequences here have the largest similarity with those obtained in the present study.

c All the base changes in brackets are from reference sequences to representative sequences obtained in the present study.
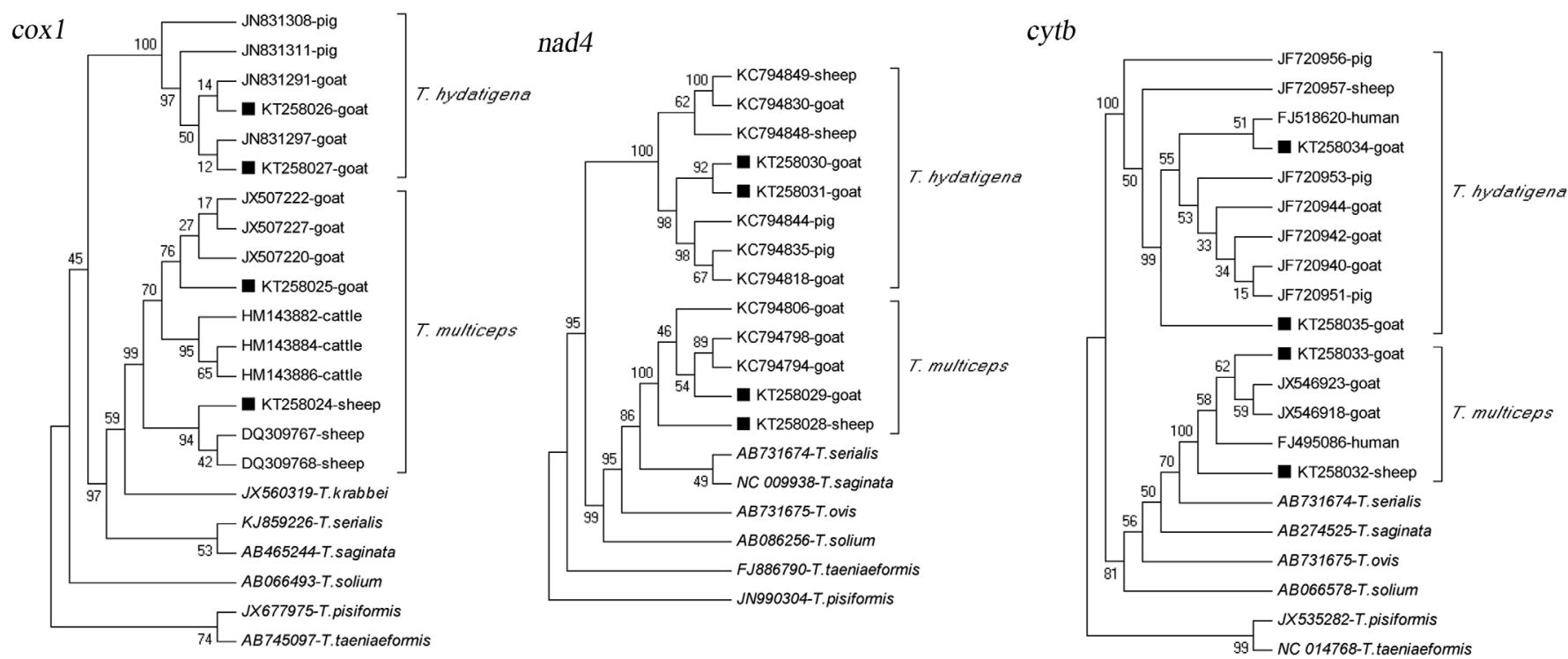

Figure 1. Phylogenetic relationship of T. multiceps and T. hydatigena isolates obtained in the present study and other T. multiceps and T. hydatigena isolates as well as other members of the genus Taenia as inferred by neighboring-joining analysis of the cox1, nad4 and $c y t b$ gene sequences based on genetic distances calculated by the Kimura 2-parameter model. The reliability of these trees was assessed using a bootstrap analysis with 1,000 replicates. The GenBank accession number and the host of origin are given for each isolate of T. hydatigena or T. multiceps. Black squares indicate the sequences of T. hydatigena or T. multiceps from the present study.

between one and $40 \mathrm{~cm}^{3}$ in goats; meanwhile, the shape of the cysts was variable according to their location: elongated when located in the middle of muscular fibers or globular if recovered in the abdominal cavities or under the skin [27]. For T. hydatigena, a cyst attached to the greater omentum was measured $15 \times 15 \times 5 \mathrm{~cm}$ in a rhesus macaque [11]. According to a necropsy report for a goat, two small-sized cysticerci vesicles (around $2 \mathrm{~cm}$ in diameter) were observed in the peritoneal cavity of a 3-year-old animal in Portugal, while the other vesicle 
(6 cm in diameter) was found inside fetal membranes [20]. So far, no reasonable explanations are given about why cysts appear markedly different in size despite the living time of cysts in hosts. This might also be related to the affected organs.

\section{Conclusion}

The present study described molecular characterization within $T$. multiceps and T. hydatigena in Inner Mongolia, China for the first time. The findings of different haplotypes at the three mt loci suggest common genetic variations of coenurus cerebralis and cysticercus tenuicollis in goats/sheep in the investigated area. These data will provide baseline information for future studies on the molecular epidemiology of T. multiceps and T. hydatigena as well as on the biological and epidemiological significance of intra-specific variations within both Taenia cestodes. However, in the present study, six coenurus cerebralis cysts were analyzed and five of them were collected from brains of goats, while the remaining one was collected from the small intestine mesentery of a sheep, which is different from a previous report that cerebral coenurosis occurred mostly in sheep and non-cerebral coenurosis mostly in goats [6]. This might be related to the small number of coenurus cerebralis cysts collected in the present study. In spite of this, based on the fact that dogs play an important role in the maintenance and the transmission of T. multiceps and T. hydatigena to animals and occasionally to humans, future work will focus on the epidemiological study of taeniasis in dogs, as well as evaluation of economic losses caused by T. multiceps and T. hydatigena. These data will also be valuable to develop suitable control strategies to avoid cestode infections in animals and humans.

\section{Competing interests}

The authors declare that they have no competing interests.

Acknowledgment. This work was supported financially by the Heilongjiang Province Education Bureau under grant No.12531266 (Aiqin Liu). The funders had no role in study design, data collection and analysis, decision to publish, or preparation of the manuscript.

\section{References}

1. Akbari M, Moazeni M, Oryan A, Sharifiyazdi H, Amrabadi O. 2015. Experimental cerebral and non-cerebral coenurosis in goats: a recent study on a comparative study on the morphological and molecular characteristics of the parasite. Veterinary Parasitology, 211(3-4), 201-207.

2. Al-Riyami S, Ioannidou E, Koehler AV, Hussain MH, AlRawahi AH, Giadinis ND, Lafi SQ, Papadopoulos E, Jabbar A. 2016. Genetic characterization of Taenia multiceps cysts from ruminants in Greece. Infection, Genetics and Evolution, 38, 110-116.
3. Avcioglu H, Yildirim A, Duzlu O, Inci A, Terim KA, Balkaya I. 2011. Prevalence and molecular characterization of bovine coenurosis from Eastern Anatolian region of Turkey. Veterinary Parasitology, 176(1), 59-64.

4. Boufana B, Scala A, Lahmar S, Pointing S, Craig PS, Dessì G, Zidda A, Pipia AP, Varcasia A. 2015. A preliminary investigation into the genetic variation and population structure of Taenia hydatigena from Sardinia, Italy. Veterinary Parasitology, 214(1-2), 67-74.

5. Bowles J, Blair D, McManus DP. 1992. Genetic variants within the genus Echinococcus identified by mitochondrial DNA sequencing. Molecular and Biochemical Parasitology, $54(2), 165-173$.

6. Christodoulopoulos G, Dinkel A, Romig T, Ebi D, Mackenstedt U, Loos-Frank B. 2016. Cerebral and noncerebral coenurosis: on the genotypic and phenotypic diversity of Taenia multiceps. Parasitology Research, 115 (12), 4543-4558.

7. Cui LZ, Da NT, Duan HD, Yang ZG. 1999. Diagnosis and investigation of cysticercosis tenuicollis in lambs. Heilongjiang Animal Science And veterinary Medicine, 7, 28. (In Chinese)

8. Dai RS, Liu GH, Song HQ, Lin RQ, Yuan ZG, Li MW, Huang SY, Liu W, Zhu XQ. 2012. Sequence variability in two mitochondrial DNA regions and internal transcribed spacer among three cestodes infecting animals and humans from China. Journal of Helminthology, 86(2), 245-251.

9. Gasser RB, Zhu X, McManus DP. 1999. NADH dehydrogenase subunit 1 and cytochrome c oxidase subunit I sequences compared for members of the genus Taenia (Cestoda). International Journal for Parasitology, 29(12), 1965-1970.

10. Haukisalmi V, Konyaev S, Lavikainen A, Isomursu M, Nakao M. 2016. Description and life-cycle of Taenia lynciscapreoli sp. n. (Cestoda, Cyclophyllidea). Zookeys, $584,1-23$.

11. Hobbs TR, Colgin LM, Maginnis GM, Lewis AD. 2003. Abdominal cysticercosis in a rhesus macaque (Macaca mulatta). Comparative Medicine, 53(5), 545-547.

12. Hoberg EP. 2006. Phylogeny of Taenia: Species definitions and origins of human parasites. Parasitology International. 55 Suppl, S 23-30.

13. Lescano AG, Zunt J. 2013. Other cestodes: sparganosis, coenurosis and Taenia crassiceps cysticercosis. Handbook of Clinical Neurology, 114(2), 335-345.

14. Li WH, Jia WZ, Qu ZG, Xie ZZ, Luo JX, Yin H, Sun X.L, Blaga R, Fu BQ. 2013. Molecular characterization of Taenia multiceps isolates from Gansu Province, China by sequencing of mitochondrial cytochrome $\mathrm{C}$ oxidase subunit 1. Korean Journal of Parasitology, 51(2), 197-201.

15. Liu GH, Lin RQ, Li MW, Liu W, Liu Y, Yuan ZG, Song HQ, Zhao GH, Zhang KX, Zhu XQ. 2011. The complete mitochondrial genomes of three cestode species of Taenia infecting animals and humans. Molecular Biology Reports, 38(4), 2249-2256.

16. McManus DP. 2006. Molecular discrimination of taeniid cestodes. Parasitology International, 55 Suppl, S31-37.

17. Mou J, Yang YD, Wei LF, Yang GY. 2010. Research progress of brain coenurosis in animals. Progress in Veterinary Medicine 31, 96-99. (In Chinese)

18. Oryan A, Akbari M, Moazeni M, Amrabadi OR. 2014. Cerebral and non-cerebral coenurosis in small ruminants. Tropical Biomedicine, 31(1), 1-16.

19. Oryan A, Moazeni M, Amrabadi O, Akbari M, Sharifiyazdi H. 2015. Comparison of distribution pattern, pathogenesis and molecular characteristics of larval stages of Taenia multiceps in sheep and goats. Small Ruminant Research. 132, 44-49. 
20. Payan-Carreira R, Silva F, Rodrigues M, dos Anjos Pires M. 2008. Cysticercus tenuicollis vesicle in fetal structures: report of a case. Reproduction in Domestic Animals, 43, 764-766.

21. Radfar MH, Tajalli S, Jalalzaden M. 2005. Prevalence and morphological characterization of Cysticercus tenuicollis (Taenia hydatigena cysticerci) from sheep and goats in Iran. Verinarski Arhiv, 75, 469-476.

22. Rostami S, Salavati R, Beech RN, Sharbatkhori M, Babaei Z, Saedi S, Harandi MF. 2013. Cytochrome c oxidase subunit 1 and $12 \mathrm{~S}$ ribosomal RNA characterization of Coenurus cerebralis from sheep in Iran. Veterinary Parasitology, 197(1-2), 141-151.

23. Rostami S, Salavati R, Beech RN, Babaei Z, Sharbatkhori M, Baneshi MR, Hajialilo E, Shad H, Harandi MF. 2015. Molecular and morphological characterization of the tapeworm Taenia hydatigena (Pallas, 1766) in sheep from Iran. Journal of Helminthology, 89(2), 150-157.

24. Scala A, Pipia AP, Dore F, Sanna G, Tamponi C, Marrosu R, Bandino E, Carmona C, Boufana B, Varcasia A. 2015. Epidemiological updates and economic losses due to Taenia hydatigena in sheep from Sardinia, Italy. Parasitology Research, 114(8), 3137-3143.

25. Sonmez B, Koroglu E, Simsek S. 2016. Molecular characterization and detection of variants of Taenia multiceps in sheep in Turkey. Parasitology, 6(2), 1-6.

26. Utuk AE, Piskin FC. 2012. Molecular detection and characterization of goat isolate of Taenia hydatigena in Turkey. Scientific World Journal, 2012, 962732.
27. Varcasia A, Jia WZ, Yan HB, Manunta ML, Pipia AP, Garippa G, Scala A, Schuster RK. 2012. Molecular characterization of subcutaneous and muscular coenurosis of goats in United Arab Emirates. Veterinary Parasitology, 190, 604-607.

28. Varcasia A, Pipia AP, Arru D, Pes AM, Tamponi C, Dore F, Garippa G, Scala A. 2013. Morphological and molecular characterization of bovine coenurosis in Sardinia, Italy. Parasitology Research, 112, 2079-2082.

29. Varcasia A, Pipia AP, Dessì G, Zidda A, Tamponi C, Pau M, Scala A, Boufana B. 2016. Morphology and genetic variability within Taenia multiceps in ruminants from Italy. Veterinary Parasitology, 223, 181-185.

30. Wang A, Wang HY, Guo XF, Chen WL, Eer DC, Wuyun G. 1996. An investigation report of helminths in wild wolves in pastoral areas of Inner Mongolia. Inner Mongolia Veterinary, 58, 8. (In Chinese).

31. Wang ZX, Wang KC, Han XP, Shen JL, Zhang LW. 2000. One human case of stomach cysticerosis tenuicollis in a child. Nature Medicine Journal of China, 80, 674 (in Chinese).

32. Xiao N, Qiu J, Nakao M, Nakaya K, Yamasaki H, Sako Y, Mamuti W, Schantz PM, Craig PS, Ito A. 2003. Short report: Identification of Echinococcus species from a yak in the Qinghai-Tibet plateau region of China. American Journal of Tropical Medicine and Hygiene 69, 445-446.

33. Zhuang DX, Fan XH, Wang A, Qian YC, Wang HY. 1994. Investigation of helminths in dogs in Yakeshi of Inner Mongolia. Inner Mongolia Veterinary, 51, 18-19. (In Chinese).

Cite this article as: Zhang Y, Zhao W, Yang D, Tian Y, Zhang W, Liu A. 2018. Genetic characterization of three mitochondrial gene sequences of goat/sheep-derived coenurus cerebralis and cysticercus tenuicollis isolates in Inner Mongolia, China. Parasite 25, 1

\section{PARASTE}

An international open-access, peer-reviewed, online journal publishing high quality papers on all aspects of human and animal parasitology

Reviews, articles and short notes may be submitted. Fields include, but are not limited to: general, medical and veterinary parasitology; morphology, including ultrastructure; parasite systematics, including entomology, acarology, helminthology and protistology, and molecular analyses; molecular biology and biochemistry; immunology of parasitic diseases; host-parasite relationships; ecology and life history of parasites; epidemiology; therapeutics; new diagnostic tools.

All papers in Parasite are published in English. Manuscripts should have a broad interest and must not have been published or submitted elsewhere. No limit is imposed on the length of manuscripts.

Parasite (open-access) continues Parasite (print and online editions, 1994-2012) and Annales de Parasitologie Humaine et Comparée (1923-1993) and is the official journal of the Société Française de Parasitologie. 